\title{
TRIBUTE
}

\section{Edward Maxwell (Max) Nicholls (1927-2011), a Key Player in the Development of the Two-Hit Model of Tumor Formation}

\author{
Alan E. Stark ${ }^{1}$ and Paulo A. Otto ${ }^{2}$ \\ ${ }^{1}$ School of Mathematics and Statistics FO7, University of Sydney, New South Wales, Sydney, \\ Australia \\ ${ }^{2}$ Department of Genetics and Evolutionary Biology, University of Sao Paulo, Sao Paulo, Brazil
}

\begin{abstract}
E. M. Nicholls (1927-2011) was a humanist, medical practitioner, human biologist, geneticist and, above all, a teacher, as well as a husband and father. He believed that he had made a fundamental contribution to the two-hit model of cancer formation. This hypothesis is associated with retinoblastoma, in particular. Nicholls presented it through his observations on neurofibromatosis. He received little credit for what he believed was his most original contribution to medical science. This note attempts to redress the balance in his favor.
\end{abstract}

Keywords: retinoblastoma, neurofibromatosis, tumors two-hit model, somatic, germinal, mutation

\section{Education and Career Outline}

Max Nicholls had his basic schooling at Crystal Brook Primary School, South Australia, Port Pirie High School, and Prince Alfred College, Adelaide where he excelled in mathematics. Instead of following a career in this area, in 1944 he enrolled at the University of Adelaide for medical studies. After graduating in 1949, he moved to northern Australia where he was directly involved with and in charge of general medical practice in a large outback area of Australia. While in the town of Mannum, where he practiced medicine for several years up to 1963, he obtained postgraduate qualifications in human genetics and in 1964 he took up an academic position at the recently opened School of Human Genetics at the University of New South Wales, where he remained until 1986, when he transferred to another department; he retired in 1992 at the age of 65.

\section{Research}

In 1967 Nicholls received the degree of MD from the University of Adelaide, having presented a thesis entitled Somatic Variability in Mammalian Pigmentation Particularly Human, with an Attempt to Relate the Phenomena Observed to Certain Inherited Conditions in Man. His thesis dealt with the genetics of pigmentation and neoplasms and was the core of a series of fruitful papers published in international periodicals between 1968 and 1973, in which Max's most important contribution by far was the 'two-hit' theory of cancer.

The idea of multiple hits in cancer had already been proposed and roughly postulated by some authors such as Nordling (1953) and van Kampen (1966), but the specific two-hit theory proposed by Nicholls $(1968,1969$ a, 1970) anticipated the one by Knudson (1971) by at least two years. Knudson published his seminal paper on the two-hit cancer hypothesis using data on retinoblastoma; although Knudson cites only the review paper by Ashley (1969) on the multiple hit cancer theory and makes no direct references to the papers by Nordling, van Kampen, and Nicholls, he alone was fully credited with the idea. The reasons for this may be many. Besides truly dedicating himself to this theme for years (see, e.g., his many references in Kern, 2002), Knudson used in his first publication the clear-cut and easily understandable example of retinoblastoma, presenting his results with a model supported by appropriate, high-quality quantitative statistical evidence.

AdDRESS FOR CORRESPONDENCE: Dr Alan E. Stark, PO Box 479, Balgowlah NSW 2093, Australia. E-mail: alans@exemail.com.au 
The question of fairly allocating priority was undertaken in the in-depth analysis of Kern (2002), who showed that Nicholls should be fully credited for the ideas: (1) that two hits are necessary, and perhaps sufficient, to initiate a single given neoplasm; (2) that two hits are needed to inactivate the two allelic copies of a gene, and at least one of these is somatic (allelic hit hypothesis); (3) that dominant inheritance patterns can be due to mutations that are functionally recessive at the tissue level (an idea Nicholls shares with van Kampen 1966).

\section{Overview}

After 1973, probably moved by the unjust lack of due recognition for his important participation in the development of the two-hit cancer theory, Nicholls' scientific interests centered on other subjects, mainly on immunology issues, a field to which he also contributed with a number of important publications.

At the end of his article; however, Kern remarks:

No sound bite or eponymous phrase can capture the full intellectual ancestry of our current theoretical understanding of the genetics and inherited recessive susceptibilities to neoplasia. There can be, however, an enhanced appreciation of the multiplicity and timespan of contributions, the inspiring cleverness of key players, and the elegance of the primary human data that permitted the resolution of challenging questions.

And Max Nicholls was beyond any reasonable doubt one of the main clever key players in contributing to this theory.

\section{Bibliography of Max Nicholls (up to 1974)}

Cooper, D. W., Lewis, H. B.M., \& Nicholls, E. M. (1965). Haptoglobin Johnson in Australian Aborigines. Nature, 208, 694.

Nicholls, E. M., Lewis, H. B., Cooper, D. W., \& Bennett, J. H. (1965). Blood group and serum protein differences in some central Australian Aborigines. American Journal of Human Genetics, 17, 293-307.

Nicholls, E. M. (1968). Genetic susceptibility and somatic mutation in the production of freckles, birthmarks and moles. Lancet, 1(7533), 71-73.

Nicholls, E. M. (1969a). Somatic variation and multiple neurofibromatosis. Human Heredity, 19, 473-479.

Nicholls, E. M. (1969b). The genetics of red hair. Human Heredity, 19, 36-42.
Nicholls, E. M. (1969c). Dopa and the red, brown and black pigments of hair and feathers. Journal of Investigative Dermatology, 53, 302-309.

Nicholls, E. M. (1970). Phacomatoses, the inheritance of cancer, and somatic mutation. Clinical Genetics, 1, 245257.

Nicholls, E. M., \& Stark, A. E. (1971a). Bayes' theorem. Medical Journal of Australia, 2, 1335-1339.

Nicholls, E. M., \& Rienits, K. G. (1971b). Tryptophan derivatives and pigment in hair of some Australian marsupials. International Journal of Biochemistry, 2, 593-603.

Nicholls, E. M. (1973a). Development and elimination of pigmented moles, and the anatomical distribution of primary malignant melanoma. Cancer, 32, 191-195.

Nicholls, E. M. (1973b). Nephroblastoma and genetic analysis. Medical Journal of Australia, 1, 457.

Nicholls, E. M. (1973c). Nephroblastoma. Medical Journal of Australia, 2, 660.

Nicholls, E. M. (1973d). Nephroblastoma. Medical Journal of Australia, 2, 1074.

Nicholls, E. M. (1973e). Pigment spotting in man and number of genes determining skin and eye color. Human Heredity, $23,1-12$.

Nicholls, E. M. (1974a). Aggregation of buffy-coat leucocytes. A simple, sensitive assay for cell-mediated immunity. Clinical \& Experimental Immunology, 17, 673-680.

Nicholls, E. M. (1974b). Histocompatibility testing 1972. Medical Journal of Australia, 2, 308.

Nicholls, E. M. (1974c). Red hair, white skin, blue eyes - Genetics of human pigmentation. Annals of Human Biology, 1,111 .

\section{References}

Ashley, D. J. B. (1969). The two 'hit' and multiple 'hit' theories of carcinogenesis. British Journal of Cancer, 23, 313328.

Kern, S. E. (2002). Whose hypothesis? Ciphering, sectorials, d lesions, freckles and the operation of Stigler's law. Cancer Biology \& Therapy, 1, 571-581.

Knudson, A. G. (1971). Mutation and cancer: Statistical study of retinoblastoma. Proceedings of the National Academy of Sciences USA, 68, 820-823.

Nordling, C. O. (1953). A new theory on the cancer-inducing mechanism. British Journal of Cancer, 7, 68-72.

van Kampen, C. (1966). A case of retinoblastoma, combined with severe mental retardation and a few other congenital anomalies, associated with complex aberrations of the karyotype. Maandschr. voor Kindergeneesk, 34, 90-95. 